\title{
Sporicidal activity of hospital disinfectants
}

\author{
J. C. KELSEY, I. H. MACKINNON, AND ISOBEL M. MAURER
}

From the Disinfection Reference Laboratory, Central Public Health Laboratory, Colindale Avenue, London

SYNOPSIS The sporicidal activity of hospital disinfectants was tested using two methods of test and two species of spores. Alcoholic hypochlorite and glutaraldehyde (Cidex) showed some sporicidal $\stackrel{\odot}{\circ}$ activity; the first was the more effective. Iodophors, formalin, and phenolics were less effective, in descending order. Chlorhexidine showed no activity.

A freshly prepared solution containing $50 \%$ methanol and sufficient sodium hypochlorite to provide 2000 parts per million available chlorine in distilled water, with a contact time of 15 minutes, is suggested for the decontamination of clean, heat-sensitive instruments except those of plated metal. It must be understood that no such method can be depended upon to sterilize.

The instruments should be rinsed in sterile water before use after decontamination.

No chemical disinfectant can be depended upon to sterilize. Some of them show sporicidal activity but even the best of them are, inevitably, a poor substitute for heat sterilization. However, their use may be unavoidable, on occasion, while heat-sensitive equipment continues to be purchased for hospitals and facilities for sterilization at lower temperatures, as with low-temperature steam and formaldehyde, or for pasteurization have not been arranged.

The present work was undertaken to compare the sporicidal activity of disinfectants commonly used in hospitals, with a view to offering advice on the treatment of heat-sensitive equipment in difficult situations. Particular attention was given to the performance of Cidex (buffered glutaraldehyde, Ethicon) in view of the claims made for its effectiveness.

Tables I, II, III, and IV name the disinfectants with their chemical categories.

\section{Test Method I: Kelsey-Sykes Test}

The disinfectants were first tested by the method of Kelsey and Sykes (1969) under 'clean' conditions, that is, in the absence of organic material, with several modifications.

In the place of the standard vegetative bacteria a suspension of spores of Bacillus subtilis, NCTC 10073, was used. The spore suspension was prepared as described by Beeby and Whitehouse (1965) for testing ethylene oxide sterilization. The spores were suspended in $90 \%$ methanol at first but for later tests they were suspended in distilled water, as Received for publication April 1974. alcoholic spores are unlikely to be present in a $\vec{\varphi}$ practical situation.

All the disinfectants, except Cidex, were diluted with distilled water instead of standard hard water. The change was made in an attempt to provide the disinfectants with more favourable conditions for activity. Cidex was used undiluted as is recommended by the manufacturers.

The Kelsey-Sykes standard contact time of eight minutes was used in the early tests but as a number of the disinfectants, including Cidex, failed the tests the contact time for these brands was extended to three hours.

The number of spores in the suspension was reduced from the standard $10^{8} / \mathrm{ml}$ to $10^{6} / \mathrm{ml}$ and $10^{4} / \mathrm{ml}$ in some of the tests to provide more favourable conditions for disinfectant activity.

The incubation time was extended from the standard 48 hours to seven days to permit a longer period of recovery.

Freshly prepared dilutions of all the disinfectants $N$ except Cidex were used for the tests. Cidex is said to remain active for 14 days after the addition of the sodium carbonate 'activator' supplied with it. Cidex c was therefore tested immediately after the addition of the activator and daily for a number of days.

The effectiveness of the recovery broth in inactivat- $\frac{}{\Phi}$ ing any carry over of disinfectant was checked, for $\stackrel{?}{+}$ all those tested, by the method described in British Standards 3286 (1960). The check was extended to make sure that the growth of the spores in the recovery broth was possible. Nutrient broth containing 3\% Tween 80 was used as recovery broth for the tests with Hibitane, Savlon, Resiguard, Roccal, 
Vanodine, Wescodyne, Betadine, Hycolin, and Tego. Nutrient broth without an added inactivator was used for the other disinfectants. It was shown to be satisfactory for all except formalin, which failed the test at $10 \%$ in spite of incomplete inactivation.

The importance of checking the suitability of the recovery conditions must be stressed. Results of the first Kelsey-Sykes tests are not reported here as they proved to be misleading. In particular, misleading results were given by the use of sodium thiosulphate in recovery broth for hypochlorites and iodophors. It was found to inhibit the growth of surviving organisms. Tween 80 was needed in the recovery broth not only for the inactivation of quaternary ammonium compounds (QACs), chlorhexidine and the ampholyte, but also for the iodophors and for one phenolic, Hycolin, which contains bacteriostatic surface active agents.

The results of the final Kelsey-Sykes tests are summarized in tables I-IV.

\section{ESTIMATION OF EFFECTIVENESS BY}

\section{KELSEY-SYKES METHOD}

Cidex (table I) failed to fulfil the claims made for it. Cidex failed in all the tests with watery spores, in spite of reduced numbers and the three-hour contact time recommended by the manufacturers. With

\begin{tabular}{llll}
\hline $\begin{array}{l}\text { Days after } \\
\text { Activation }\end{array}$ & $\begin{array}{l}\text { Alcoholic Spores } \\
\left(10^{8} / \mathrm{ml}\right)\end{array}$ & $\begin{array}{l}\text { Watery Spores } \\
\left(10^{8} / \mathrm{ml}\right)\end{array}$ & $\begin{array}{l}\text { Watery Spores } \\
\left(10^{8} / \mathrm{ml}\right)\end{array}$ \\
\hline 0 & Passed & Failed & Failed \\
1 & Passed & Failed & Failed \\
2 & Passed & Failed & Failed \\
3 & Failed & Failed & Failed \\
4 & Failed & Failed & Failed \\
5 & Failed & Not tested & Not tested \\
6 & Failed & Not tested & Not tested \\
7 & Failed & Not tested & Not tested \\
8 & Failed & Not tested & Not tested \\
9 & Failed & Not tested & Not tested \\
10 & Failed & Not tested & Not tested \\
11 & Failed & Not tested & Not tested \\
12 & Failed & Not tested & Not tested \\
\hline
\end{tabular}

Table I Results of modified Kelsey-Sykes test ${ }^{1}$

${ }^{1}$ Test organism, B. subtilis spores; contact time, three hours; disinfectant, Cidex undiluted (glutaraldehyde $2 \%$ ) alcoholic spores Cidex passed the test on the first three days after activation. It failed on each of the following 10 days.

Alcoholic spores do not present a realistic challenge.

Many other disinfectants (table II) failed the test at a concentration of $10 \%$ with three hours' contact. Failures were seen with alcoholic spores and with reduced numbers of watery spores.

The disinfectants which failed included formalin, Tego, Hibitane, Roccal, Resiguard, Savlon, Clearsol, Dettol, Hycolin, Izal, PD114, Stericol, and Sudol.

Hypochlorites, Chloros, and Domestos (table III) passed the test with the standard contact time of eight minutes. The passing concentrations with alcoholic spores were reasonably low, but were much higher with watery spores even in reduced numbers. Iodophors Betadine, Vanodine, and Wescodyne failed the test with the eight-minute standard contact time. Failure was complete at all concentrations up

\begin{tabular}{|c|c|c|c|}
\hline $\begin{array}{l}\text { Disinfectants } \\
\text { Tested }\end{array}$ & $\begin{array}{l}\text { Alcoholic } \\
\text { Spores } \\
\left(10^{8} / \mathrm{ml}\right)\end{array}$ & $\begin{array}{l}\text { Watery } \\
\text { Spores } \\
\left(10^{8} / \mathrm{ml}\right)\end{array}$ & $\begin{array}{l}\text { Watery } \\
\text { Spores } \\
\left(10^{6} / \mathrm{ml}\right)\end{array}$ \\
\hline $\begin{array}{l}\text { Aldehyde } \\
\text { formalin } \\
\text { Ampholyte } \\
\text { Tego MHG } \\
\text { Diguanide } \\
\text { Hibitane } \\
\text { (chlorhexidine) } \\
\text { Quaternary } \\
\text { ammonium } \\
\text { compound (QAC) } \\
\text { Roccal } \\
\text { Diguanide/QAC } \\
\text { Resiguard } \\
\text { Savlon } \\
\text { Phenolics } \\
\text { Clearsol } \\
\text { Dettol } \\
\text { Hycolin } \\
\text { Izal } \\
\text { PD114 } \\
\text { Stericol } \\
\text { Sudol }\end{array}$ & 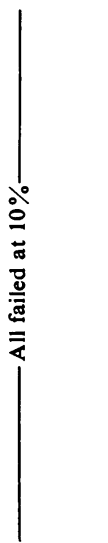 & 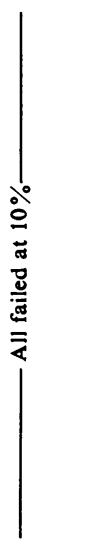 & 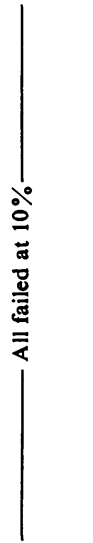 \\
\hline
\end{tabular}

Table II Results of modified Kelsey-Sykes test ${ }^{1}$

${ }^{1}$ Test organism, B. subtilis spores; contact time, three hours; disinfectants diluted in distilled water

\begin{tabular}{|c|c|c|c|c|}
\hline Disinfectants Tested & $\begin{array}{l}\text { Alcoholic Spores } \\
\left(10^{8} / \mathrm{ml}\right)\end{array}$ & $\begin{array}{l}\text { Watery Spores } \\
\left(10^{8} / \mathrm{ml}\right)\end{array}$ & $\begin{array}{l}\text { Watery Spores } \\
\left(10^{\circ} / \mathrm{ml}\right)\end{array}$ & $\begin{array}{l}\text { Watery Spores } \\
\left(10^{4} / \mathrm{ml}\right)\end{array}$ \\
\hline \multicolumn{5}{|l|}{ Hypochlorites } \\
\hline $\begin{array}{l}\text { Chloros } \\
\text { Domestos }\end{array}$ & $\begin{array}{l}\text { Pass } 2.0 \% \\
\text { Pass } 2.0 \%\end{array}$ & $\begin{array}{l}\text { Pass } 30.0 \% \\
\text { Pass } 30.0 \%\end{array}$ & $\begin{array}{l}\text { Pass } 12.5 \% \\
\text { Pass } 10.0 \%\end{array}$ & \\
\hline \multicolumn{5}{|l|}{ Iodophors } \\
\hline $\begin{array}{l}\text { Betadine (povidone iodine) } \\
\text { Vanodine } \\
\text { Wescodyne }\end{array}$ & $\begin{array}{l}\text { Fail } 100.0 \% \\
\text { Fail } 100.0 \% \\
\text { Fail } 100.0 \%\end{array}$ & $\begin{array}{l}\text { Fail } 100.0 \% \\
\text { Fail } 100.0 \% \\
\text { Fail } 100.0 \%\end{array}$ & & $\begin{array}{l}\text { Fail } 100.0 \% \\
\text { Fail } 100.0 \% \\
\text { Fail } 100.0 \%\end{array}$ \\
\hline
\end{tabular}

Table III Results of modified Kelsey-Sykes test ${ }^{1}$

${ }^{1}$ Test organism, B. subtilis spores; contact time, eight minutes; disinfectants diluted in distilled water. 


\begin{tabular}{|c|c|c|c|}
\hline Disinfectants Tested & Contact Time & Methanol Concentration $(\%)$ & $\begin{array}{l}\text { Results with Watery Spores } \\
(10 \% / \mathrm{ml})\end{array}$ \\
\hline \multicolumn{4}{|l|}{ Hypochlorite } \\
\hline $\begin{array}{l}\text { Chloros } \\
\text { Choros } \\
\text { Iodophors }\end{array}$ & $\begin{array}{l}8 \mathrm{~min} \\
8 \mathrm{~min}\end{array}$ & $\begin{array}{l}50 \\
25\end{array}$ & $\begin{array}{l}\text { Pass } 2.0 \% \\
\text { Pass } 2.0 \%\end{array}$ \\
\hline $\begin{array}{l}\text { Betadine (povidone iodine) } \\
\text { Vanodine } \\
\text { Wescodyne }\end{array}$ & $\begin{array}{l}3 \text { hours } \\
3 \text { hours } \\
3 \text { hours }\end{array}$ & $\begin{array}{l}50 \\
50 \\
50\end{array}$ & $\begin{array}{l}\text { Fail } 50.0 \% \\
\text { Fail } 50.0 \% \\
\text { Fail } 50.0 \%\end{array}$ \\
\hline
\end{tabular}

Table IV Results of modified Kelsey-Sykes test ${ }^{1}$

1Test organism, B. subtilis spores; disinfectants diluted in methanol/distilled water

to $100 \%$, with alcoholic spores and with reduced numbers of watery spores.

In alcoholic dilutions with watery spores, Chloros (table IV) passed the test, with eight minutes' contact, at $2 \%$. The iodophors, in alcoholic dilutions, were less successful in three hours than the hypochlorite was in eight minutes.

\section{Test Method II: Survivor Counts}

The Kelsey-Sykes test is recognized as a stern, though realistic, method of assessment. Further work was therefore carried out to measure, by survivor counts, sporicidal activity which was possibly too slight to show up in that test. Spores of the following organisms were used: Bacillus subtilis NCTC 10073, Bacillus pumilus NCTC 10327, Clostridium tetani NCTC 9569, Clostridium bifermentans, Luton Public Health Laboratory collection.

Early attempts to grow spores for testing purposes on a chemically defined medium were later abandoned as the growth was poor. First the medium of Wright and Mundy (1960) was used solidified with $1.3 \%$ agar. The formula was varied by exclusion of some amino acids and increased concentrations of others, following the work of Hachisuka (1955). The ammonium base medium of Knight (1950) also proved unsuccessful as described and with variations.

Finally spores of the two Bacillus species were grown as described by Beeby and Whitehouse (1965) with the sole difference that for $B$. pumilus the initial incubation period was followed by a holding period at $4^{\circ} \mathrm{C}$ for seven days before harvesting.

Columbia agar base was used as a sporulation medium for $\mathrm{Cl}$. bifermentans and the egg yolk medium of Phillips (1973) for $\mathrm{Cl}$. tetani. Clostridial spores were harvested, after four days' growth at $37^{\circ} \mathrm{C}$, in the same way as the spores of the Bacillus species. $\mathrm{Cl}$. bifermentans was heat shocked at $70^{\circ} \mathrm{C}$ and $\mathrm{Cl}$. tetani at $80^{\circ} \mathrm{C}$, both for 10 minutes. Stringent anaerobic conditions were used for all work with Clostridial spores.

All the spores, after washing, were suspended in distilled water and stored at $4^{\circ} \mathrm{C}$. There was no apparent increase in the sensitivity of the spores during storage. All the suspensions used in tests contained at least $95 \%$ spores in the total population as seen by microscopy.

Test method II was used for a hypochlorite, an iodophor, formalin, methanol, chlorhexidine, a phenolic, and Cidex. Freshly prepared dilutions of all the disinfectants, except Cidex, were used. Distilled water was used for dilutions. Methanol was included in some dilutions as in previous tests, the spores suspended in methanol were more easily killed than the watery spores. Cidex was used undiluted. It was tested immediately after the addition of the activator and on several subsequent days.

Further tests were carried out with hypochlorites and other alcohols. It is hoped to report the results separately.

The tests were carried out at room temperature. One $\mathrm{ml}$ spore suspension was added to $9 \mathrm{ml}$ disinfectant. At timed intervals $1 \mathrm{ml}$ spore/disinfectant suspension was withdrawn and added to 9 mlnutrient broth diluent. The broth had been shown, by British Standards $3286(1960)$, to be an adequate inactivator for all the disinfectants (except formalin) in survivor count tests where surviving organisms are not required to grow in the inactivating medium.

Drops of diluted spore/disinfectant suspension were transferred to recovery plates, with a 50dropper pipette. The surviving spores of Bacillus species were recovered on $5 \%$ horse blood agar. The Clostridial survivors were recovered on Columbia agar enriched with $5 \%$ horse blood.

All the recovery plates were incubated at $32^{\circ} \mathrm{C}$ for several days until no further increase in the count on the plate was seen. On occasions up to seven days incubation was needed.

The results of survivor counts are shown in figures 1-6.

ESTIMATION OF EFFECTIVENESS BY SUR VIVOR. COUNTS

Watery Chloros at $2 \%$ is an effective sporicide in the presence of Clostridia in 10 minutes, but is ineffective with Bacillus species in half an hour (fig 1). 
An alcoholic solution of Chloros is more sporicidal than a watery one (figs 2,3 , and 4 ). Spores of $B$. subtilis were killed more slowly than the others tested, but a $2 \%$ Chloros, $50 \%$ methanol solution

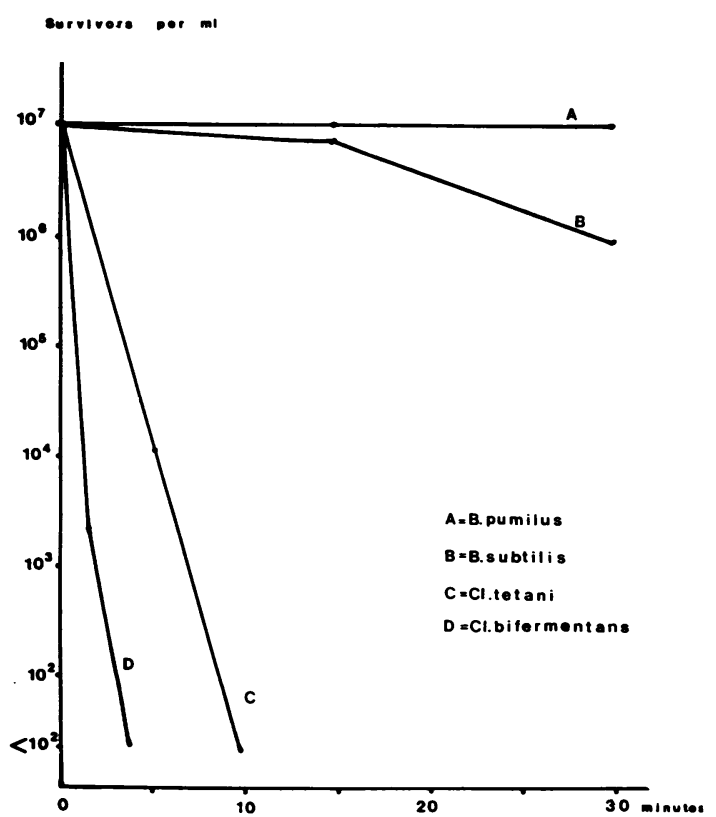

Fig 1 Watery hypochlorite (Chloros 2\%).

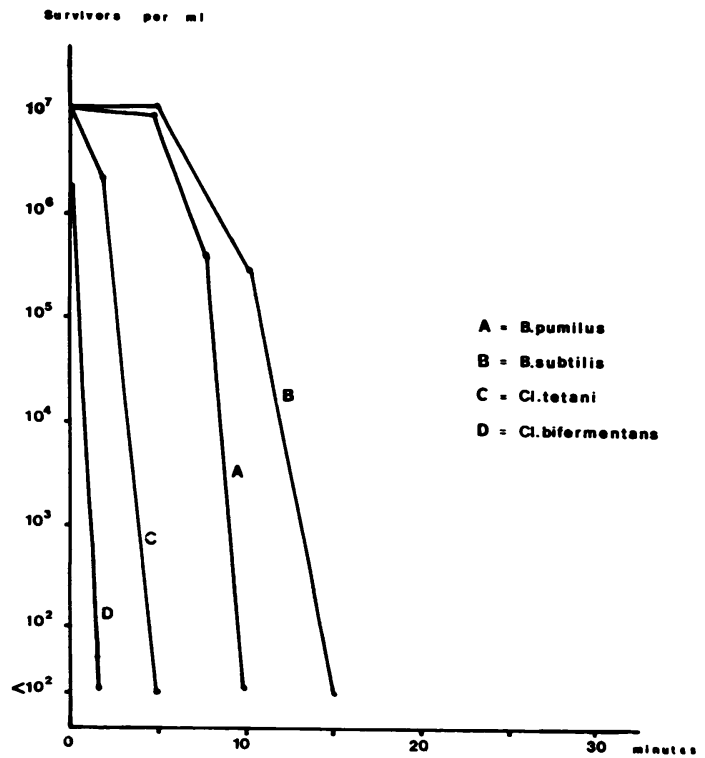

Fig 2 Methanol/hypochlorite (Chloros 2\%; methanol $25 \%$ ). killed them within 10 minutes. The methanol solution without hypochlorite is ineffective.

Cidex was reasonably effective on the day of activation but effectiveness was steadily reduced during the following days (fig 5). The claim that Cidex continues effective for 14 days after inactivation may be misleading as it does not continue equally effective. On the thirteenth day more than six hours are needed for a kill equal to that accomplished in three hours on the day of activation.

Two per cent Chloros in $50 \%$ methanol is more successful in eight minutes than Cidex is in three hours on the day of activation.

Alcoholic Wescodyne (fig 6) is more effective than watery, but alcoholic Wescodyne is far less effective than alcoholic Chloros as shown in figure 3.

During three hours Hibitane in both watery and alcoholic solution showed no signs of sporicidal activity (fig 7).

Hycolin showed very slight activity in alcoholic solution but none in watery.

Formalin, tested without an inactivator, appeared more effective in watery solution than in alcoholic, as has been shown by Rubbo and Gardner (1965) but the level of sporicidal activity is too low to be useful. Dilution in nutrient broth was used in this work as it proved less inhibiting to $B$. subtilis than sodium bisulphite or dimedone and morpholine. Complete inactivation of formalin might show the true level of sporicidal activity to be even lower than it now appears.

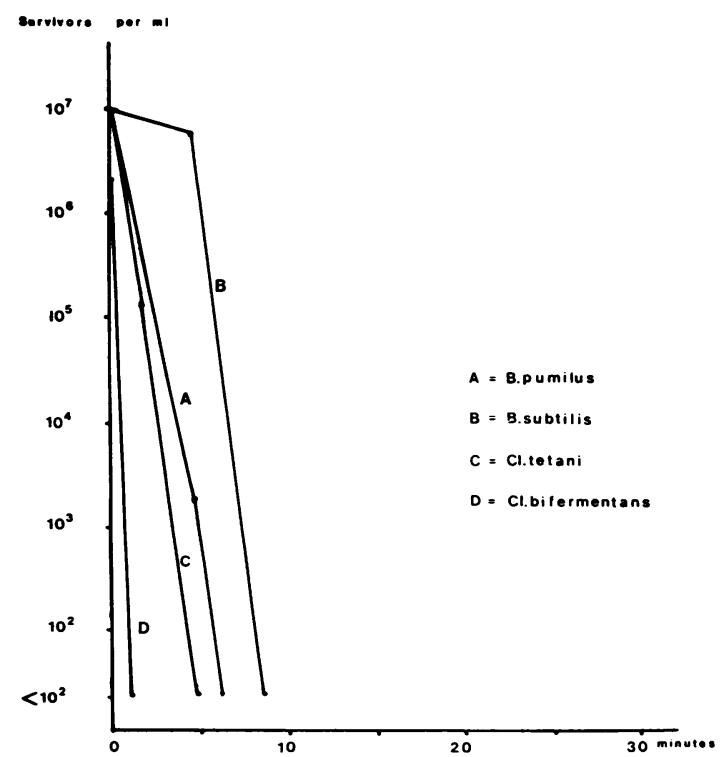

Fig 3 Methanol/hypochlorite (Chloros 2\%; methanol $50 \%$ ). 


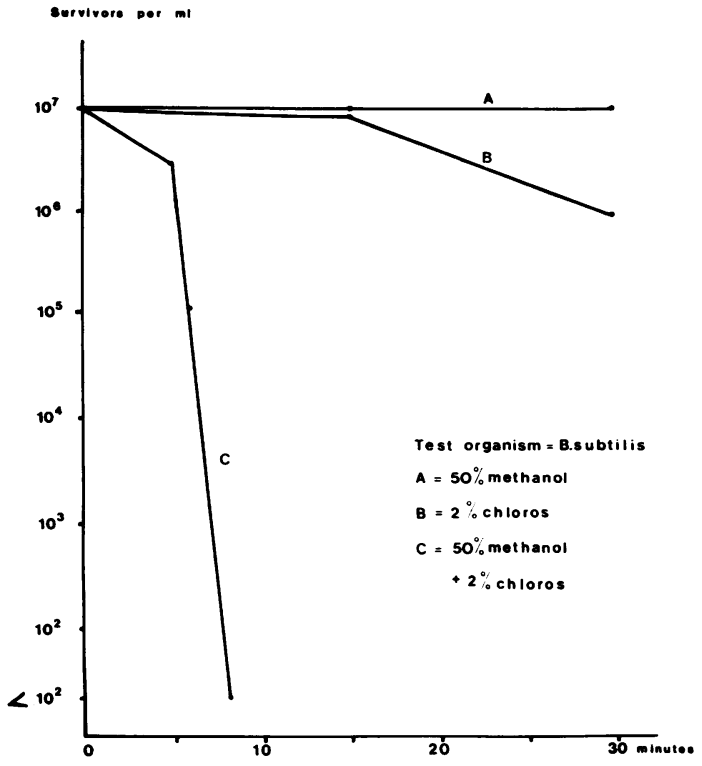

Fig 4 Methanol, hypochlorite, and methanol! hypochlorite.

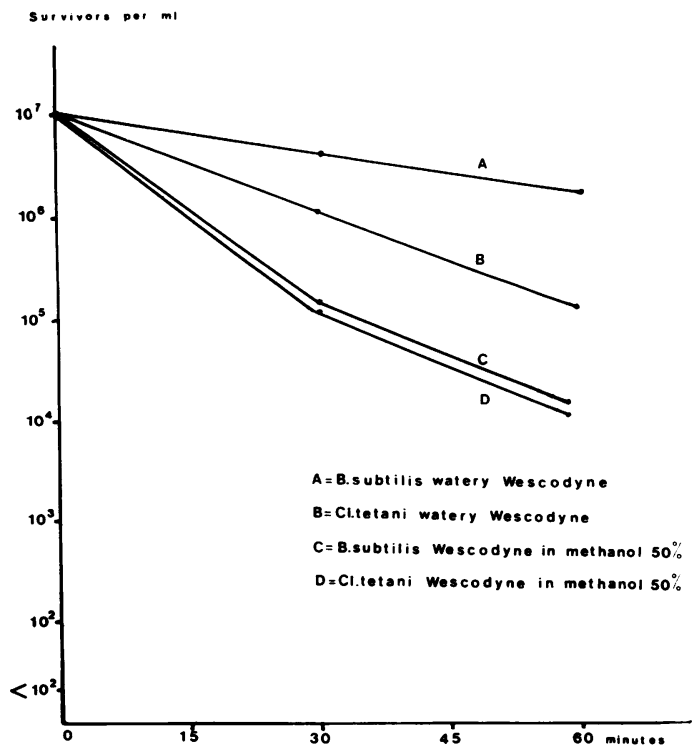

Fig 6 Methanol/iodophor and watery iodophor. Wescodyne $10 \%$.

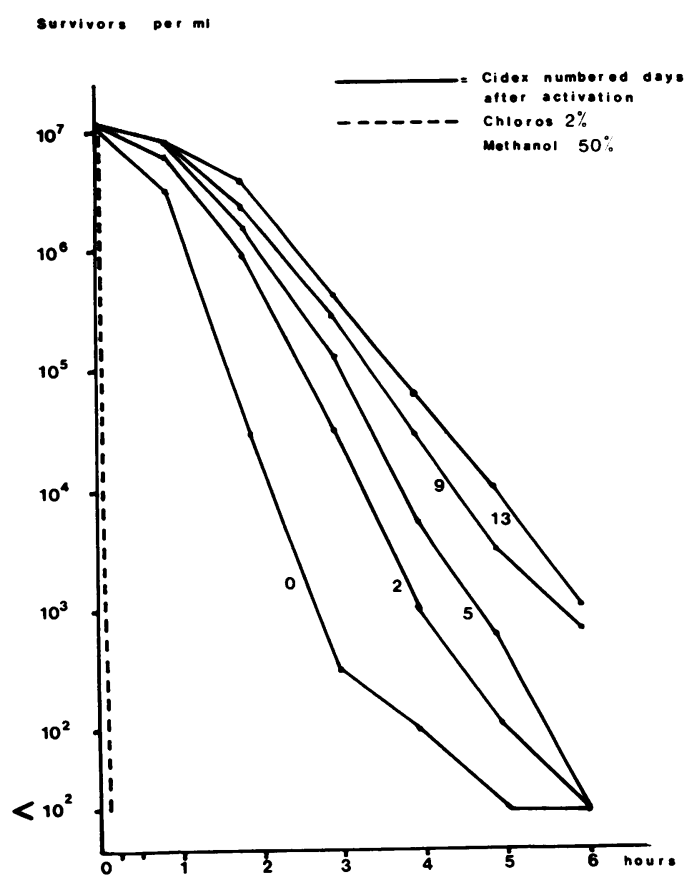

Fig 5 Cidex and methanol/hypochlorite. The test organism was $\mathrm{B}$. subtilis.

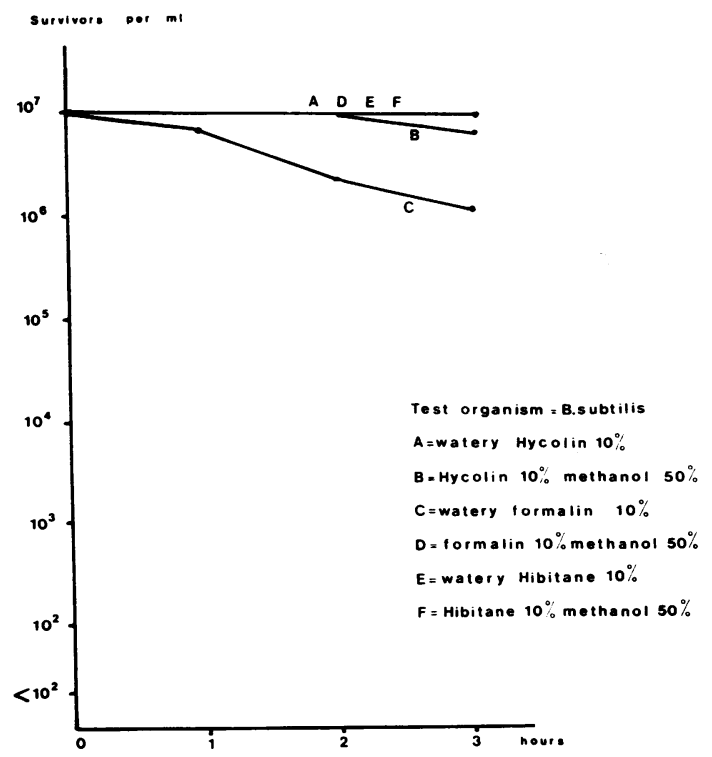

Fig 7 A phenolic, formalin, and chlorhexidine. 


\section{Practical Applications}

The possibility of damage to instruments must be considered before a chemical disinfectant may, usefully, be recommended as a sporicide. Cystoscopes were therefore immersed for four hours in a freshly prepared solution containing $2 \%$ Chloros and $50 \%$ methanol in distilled water.

The bulbs, lenses, or mirror and the cement fixing of these items appeared unaffected and visibility was not impaired. Plated metal on some old cystoscopes was corroded in a few minutes but stainless steel was unaffected in the four hours.

Scissors and forceps of stainless steel to British Standards 970 (1955) were immersed in a similar solution for two hours. After rinsing and drying, no sign of corrosion was found. Non-stainless steel and brass were soon corroded by the solution but aluminium was not.

The sporicidal activity of the alcoholic hypochlorite solution was checked in a simulated practical situation.

Drops of a suspension of $B$. subtilis spores, prepared as in test method $I$ and diluted either in horse serum or in distilled water, were dried on microscope slides. The slides were immersed either in Cidex or in the methanol hypochlorite solution and transferred at fixed times to petri dishes containing $50 \mathrm{ml}$ Tween 80 broth. The slides were incubated in the dishes of broth at $32^{\circ} \mathrm{C}$ for up to seven days.

Each slide originally carried $10^{3}$ viable spores. The spores dried from serum were found to be particularly resistant. Some survived three hours' immersion in either the alcoholic hypochlorite or in Cidex. Spores dried from distilled water were more easily killed. Usually there were no survivors after 15 minutes' immersion in the alcoholic hypochlorite or three hours' immersion in Cidex, but the results showed variations. It would seem almost impossible to design a reproducible test on these lines but the work is worth mentioning as a reminder that instruments must be cleaned before immersion in a disinfectant which is intended to be sporicidal.

\section{Discussion}

It would seem that tests of the sporicidal activity of disinfectants are, for practical purposes, best performed by pessimists. Failures in killing spores may be accepted as such but apparent success must be questioned. Growth of the test organism in the recovery medium provides firm evidence of the disinfectant's failure in killing the spores. However, absence of growth in the recovery medium should not necessarily be taken as firm evidence that the disinfectant has succeeded in killing spores. Absence of growth may mean that the best conditions for growth of surviving spores have not been provided. Russell (1971) has stressed the need to provide adequate recovery and revival conditions for treated spores.

During this work many of the earlier test results which showed no growth of the test organisms were discarded because later tests, with changes in recovery conditions, made it possible for more of the surviving spores to grow. No changes in conditions can produce growth of organisms which have been killed but changed conditions may be more favourable to the growth of survivors.

The present work has been undertaken in an attempt to give informed advice to hospital staff who are seeking a disinfectant which will kill spores in a practicable time at reasonable cost. It has been shown that several disinfectants commonly used as sporicides are likely to be ineffective. Glutaraldehyde as Cidex has proved a poor sporicide in the recommended three hours, unless it is freshly activated, although Munton and Russell (1971) have reported more favourable results with other brands of glutaraldehyde. Iodophors are much inferior to hypochlorites. Formalin, phenolics, and others show little activity.

These findings are depressing and are not in line with some publications. It is suggested that apparent sporicidal activity, which has been reported and which is not supported in this work, may be explained in part by failures in providing adequate recovery conditions. Not all authors give full details of technique. Roberts (1970) has shown that the recovery of damaged spores is not a simple matter.

The need to check an inactivator in detail is not always understood. The inactivator must be checked with the particular organism used in the disinfectant test and with each concentration of the disinfectant tested. The inactivation of aldehydes presents a problem which has not been solved here. Sodium bisulphite has been suggested as an inactivator but it has been found to inhibit the growth of many organisms. In the present tests dilution in nutrient broth succeeded in inactivating Cidex in the presence of $B$. subtilis spores, although it had not, in other work, been found fully effective with Pseudomonas aeruginosa. Formalin at $10 \%$ was not fully inactivated by nutrient broth in the presence of $B$. subtilis spores, but many surviving spores grew after contact with the formalin and the problem of inactivation was put aside for the time.

Sodium thiosulphate, the usual inactivator for halogen disinfectants, has been found to inhibit the growth of some organisms, as demonstrated by Gross and Huff (1973) and also by Kayser and van 
der Ploeg (1965). Hypochlorites which are detergentfree appear to be effectively inactivated by nutrient broth even at high concentrations. The iodophors need nutrient broth containing Tween 80 for effective inactivation.

There is a possibility that different sporulation media produce spores with different resistance to disinfectants. In order to ensure reproducibility of the Kelsey-Sykes test it has been found necessary to use a chemically defined medium for growing the non-sporing $P$. aeruginosa before contact with the disinfectant. Attempts to grow spores on a chemically defined medium for the present work, were unsuccessful. The numbers of spores grown were too few for a meaningful test.

Some sporicidal activity is very slow. Sykes (1970) prolonged contact between spores and disinfectants for several days but disinfection which must be continued for days would be impractical in a hospital.

Until a standard method of testing sporicidal activity is devised there is likely to be some disagreement about the effectiveness of disinfectants. However, for the present purpose it is sufficient to show that many disinfectants have failed to kill spores in a practicable time, in spite of dilution in distilled water and the absence of organic material. Only the methanol hypochlorite appears to have achieved a high level of sporicidal activity, in 10 minutes and at reasonable cost. In general corrosion does not appear to be a problem. If Cidex is to be used effectively a fresh solution must be activated each day and at least three hours' contact must be allowed.

Regrettably, these findings are not as helpful as they may appear. They cannot be interpreted as a reliable alternative to sterilization. The method of counting surviving spores in method II does not show up a total kill. Absence of growth on recovery plates means less than 100 survivors per millilitre of solution, a standard which is not sterility.

A further difficulty has long been known. Spores which have dried on a surface, as normally found in a hospital situation, are more difficult to kill than spores suspended in a fluid, as in a standard laboratory test. There are no standard tests for disinfectant activity on organisms dried on surfaces. The methanol hypochlorite solution which was successful in the suspension tests was apparently less successful when applied to spores dried on slide surfaces as a practical check. However, no growth in the recovery broth may be taken as evidence of a sterile slide.
Where sporicidal activity is desired, instruments must first be washed and immersion in methanol hypochlorite solution must be continued for at least 15 minutes, or in Cidex, which is freshly activated, for at least three hours. Cidex which is more than one day old cannot be recommended.

Further work on sporulation media and on recovery conditions may show that neither methanol hypochlorite nor the slower, more expensive Cidex are as effective as they now appear. They cannot be depended upon to provide a method of sterilization.

We are indebted to our colleagues in the Public Health Laboratory Service for their practical help and advice.

Dr A. T. Willis and Mrs Kate Williams have given guidance on anaerobic work and have lent equipment. $\mathrm{Mr}$ K. D. Phillips has given advice on the growth of $\mathrm{Cl}$. tetani spores and $\mathrm{Mr} \mathrm{S}$. J. Line on the growth of $B$. pumilus spores. Dr Mair E. M. Thomas has given help with practical checks.

\section{References}

Beeby, M. M., and Whitehouse, C. E. (1965). A bacterial spore test piece for the control of ethylene oxide sterilization. J. appl. Bact., 28 (3), 349-360.

British Standards Institution (1955). Wrought steels in the form of bars, billets and forgings up to 6 in ruling section for automobile and general engineering purposes, 3rd revision. BS970 British Standards Institution, London.

British Standards Institution (1960). Method for laboratory evaluation of disinfectant activity of quaternary ammonium compounds by suspension test proceedure. BS3286. British Standards Institution, London.

Gross, A., and Huff, M. B. (1973). lodine inactivating agent in surgical scrub testing. Arch. Surg., 106, 175-178.

Hachisuka, Y., Asano, N., Kato, N., Okajima, M., Kitaori, M., and Kuno, T. (1955). Studies on spore germination. 1. Effects of nitrogen sources on spore germination. J. Bact., 69, 399-406.

Kayser, A., and van der Ploeg, G. (1965). Growth inhibition of Staphylococci by sodium thiosulphate. J. appl. Bact., 28, 286-293.

Kelsey, J. C., and Sykes, G. (1969). A new test for the assessment of disinfectants with particular reference to their use in hospitals. Pharmaceutical J., 202, 607-609.

Knight, B. C. J. G., and Proom, H. (1950). A comparative survey of the nutrition and physiology of mesophilic species in the genus Bacillus. J. gen. Microbiol., 4, 508-538.

Munton, T. J., and Russell, A. D. (1971). Glutaraldehyde as a bactericidal agent. Brit. med. J., 3, 372-373.

Phillips, K. D. (1973). Personal communication.

Roberts, T. A. (1970). Symposium on bacterial spores. VII. Recovering spores damaged by heat, ionizing radiations or ethylene oxide. J. appl. Bact., 33 (1), 74-94.

Rubbo, S. D., and Gardner, J. F. (1965). A Review of Sterilization and Disinfection, 127-128. Lloyd-Luke, London.

Russell, A. D. (1971). The destruction of bacterial spores. In Inhibition and Destruction of the Microbial Cell, edited by W. B. Hugo. Academic Press, New York and London.

Sykes, G. (1970). Symposium on bacterial spores: XII. The sporicidal properties of chemical disinfectants. J. appl. Bact., 33 (1), 147-156.

Wright, E. S., and Mundy, R. A. (1960). Defined medium for phenol coefficient tests with Salmonella typhosa and Staphylococcus aureus. J. Bact., 80, 279-280. 